\title{
Community health workers' attitudes, practices and perceptions towards the COVID-19 pandemic in Brazilian low-income communities
}

\author{
Nilson do Rosário Costa ${ }^{\mathrm{a}}$, Hugo Bellas ${ }^{\mathrm{b}}$, Paulo Roberto Fagundes da Silva ${ }^{\mathrm{a}}$, \\ Paulo Victor Rodrigues de Carvalho ${ }^{\mathrm{c}, *}$, Deborah Uhr ${ }^{\mathrm{d}}$, Cristine Vieira ${ }^{\mathrm{a}}$ and Alessandro Jatobáb \\ ${ }^{a}$ Escola Nacional de Saúde Pública Sergio Arouca - ENSP, Fundação Oswaldo Cruz - FIOCRUZ, Rio de Janeiro, \\ RJ, Brazil \\ ${ }^{\mathrm{b}}$ Centro de Estudos Estratégicos, Fundação Oswaldo Cruz - FIOCRUZ, Rio de Janeiro, RJ, Brazil \\ ${ }^{\mathrm{c}}$ Instituto de Engenharia Nuclear - IEN, Comissão Nacional de Energia Nuclear - CNEN, Rio de Janeiro, RJ, \\ Brazil \\ ${ }^{\mathrm{d}}$ Universidade Federal Rural do Rio de Janeiro, Rio de Janeiro, RJ, Brazil
}

Received 1 October 2020

Accepted 8 December 2020

\begin{abstract}
.
BACKGROUND: Community Health Workers (CHW) are a category of social workers described in many countries' health systems as responsible for engaging people in their residences and communities, and other non-clinical spaces to enable access to health services, especially in low-income areas. These professionals have been exposed to numerous new risks during the COVID-19 pandemic.

OBJECTIVE: This study describes how the COVID-19 pandemic is perceived by CHWs who work in poor communities or slums in Brazil.

METHODS: We conducted an online survey with a random sample of 775 CHWs operating in 368 municipalities of the 26 Brazilian states. At a confidence level of $95 \%$, results of the survey were subject to a maximum sampling error of $4 \%$.

RESULTS: Our data indicate that the negationist agenda increases the challenges to the performance of CHWs within lowincome communities, preventing the consensus on the necessity of social distancing, business closures and other measures to face the COVID-19 pandemic.

CONCLUSION: The pandemic imposes unexpected challenges on the usual modes of interaction of public health officers with poor communities. This study provides evidence that these challenges have been ignored or minimized in Brazilian policy prescriptions for primary care in the face of the COVID-19 pandemic.
\end{abstract}

Keywords: Primary health care, social distancing, sociocultural territory

*Address for correspondence: Paulo Victor Rodrigues de Carvalho, D.Sc., Instituto de Engenharia Nuclear - IEN, Comissão Nacional de Energia Nuclear - CNEN, Rio de Janeiro, RJ, Brazil. E-mail: paulov@ien.gov.

\section{Introduction}

Despite some particularities, Community Health Workers (CHW) are described in many countries' health care frameworks as responsible for engaging people in their residences and communities, and other non-clinical spaces in order to enable access to health 
services, especially in low-income areas [1-4]. The Brazilian National Primary Care Policy highlights the role of the CHWs in performing house calls, promotion of health, data collection on health conditions of communities, and active epidemiological surveillance $[5,6]$.

The role of CHWs in the framework of Primary Health Care (PHC) is of paramount importance, especially during events that pose pressure over the health system, such as outbreaks, e.g. Dengue, Yellow Fever, Chikungunya, and Zika, H1N1 and more recently, COVID-19. Moreover, CHWs are important in educating the population about measures to mitigate the risk of poor communities becoming massive disease dissemination hotspots [7].

The uncontrolled trajectory of the new Coronavirus in Brazil has led to wide concern due to the lack of consensus on how to manage the pandemic in a scenario of negationism of the seriousness of the disease from the government. Still, little is known about how the Brazilian government's erratic conduct has impacted the feasibility of public agents' activity and the adherence of the population to social distancing measures.

The Brazilian unified health system (SUS) was created as a decentralized system, with a pact between the Federal, state, and municipal governments that organized roles and responsibilities and promoted PHC [8]. However, with COVID-19, the federal government has threatened to disqualify the pandemic prevention measures recommended by some regional and municipal governments, especially the ones related to social distancing and business closures. The Brazilian Supreme Court had to intervene, ratifying the authority of local governments in deciding on isolation, social distancing, and quarantine, and business closures, rejecting the Federal Executive's attempt to centralize such decisions [9].

Prior to the COVID-19 pandemic, coordinated action among the state entities enabled the breadth and effectiveness of PHC in Brazil. Since 1994, as part of Brazil's Family Healthcare Strategy (FHS), municipal governments have offered economic incentives to doctors who choose to pursue primary care, expanding the provision of health services and reducing dependence on hospital care. Such policies that support PHC nationally changed how healthcare is funded and delivered, in addition to affecting care practices [10].

The growth of the number of CHWs in Brazil is associated with the public health sector's focus on local, decentralized, PHC. Under the FHS, PHC is delivered by multidisciplinary teams, formed with a doctor, a nurse, an orderly, and four to six CHWs. CHWs are the interface between the health team and the population. They organize disease prevention and health promotion activities, register patients, provide guidance on the use of services, and conduct house calls to identify high-risk situations. CHWs are recruited among the residents of the community, must be at least elementary educated, 18 years old, and work full-time [11-13].

Before recent changes in the Brazilian primary care policy, each FHS team was responsible for a geographical area encompassing 600 to 800 families [13]. CHWs were typically employed as public servants or hired by third sector organizations $[11,12$, 14]. However, in 2017, when the Ministry of Health published a new policy for PHC with the agreement of state and municipal governments, the presence of the $\mathrm{CHW}$ on the PHC team became no longer mandatory [11].

Regarding major challenges faced, the literature points out that despite usually living in the area under the responsibility of their primary care clinics, CHWs are not trained to handle highly complex social concerns. Residents of low-income communities in Brazil are typically affected by violence, drug traffic, precarious housing and hygiene conditions, and extreme poverty [15]. Such social complexity is likely to lead to a high incidence of exhaustion and mental disorders among CHWs [14]. Furthermore, CHWs dedicate a large portion of their time to bureaucratic tasks, such as organizing medical records, recording weights during medical appointments, preparing facilities for activities, and organizing queues, leaving behind their role as health educators and promoters.

However, even though limited by such difficulties, CHWs could still potentially enhance adherence to social distancing in low-income communities. Márcia Castro, for example, recalls that faced with the evident failure to control the pandemic by the end of May 2020, "CHWs could have been employed to identify and isolate infected residents in low-income communities" [16]. Likewise, according to the Oswaldo Cruz Foundation technical report, CHWs could identify potential cases and their relations and, if possible, contacts they had in the previous 14 days, in order to recommend quarantine and other measures to reduce the spread of COVID-19 within poor communities. Similarly, CHWs could collect information on how to contact residents 
via phone and Internet to organize "online visits" [17].

Notably however, there are certain barriers to putting CHWs in these roles. In addition to the complexity of delivering health to residents in low-income communities in Brazil, there is a political barrier, that the Brazilian Federal federal government does not consider the COVID-19 pandemic to be an extreme risk event [18].

The negationism of the government hinders public perception of the risk of the pandemic. It therefore weakens the initiatives of state and municipal governments, and populations concerning social distancing. By identifying social distancing as the primary cause of Brazil's economic problems, negationism minimizes the impact of the pandemic on people's long term health conditions, as risk is determined not only by individual decision-making, but also by collective perception of danger and societal dynamics [19].

As an additional element that weakens social mobilization, it is worth noting that the lack of scientific consensus within the biomedical field on how to control the pandemic, which also enforces negationism. Strictly pharmacological intervention (vaccines and antivirals), which is typically the biomedical cornerstone during epidemics, has not been effective in controlling the spread of SARS-CoV-2 or reducing its lethality so far. As observed worldwide, it is up to national governments to implement nonpharmacological solutions that rely on individuals voluntarily adhering to social distancing and business closures.

Importantly, the majority of the Brazilian public health community recognizes that delayed adoption of social distancing influenced the rapid spread of SARS-CoV-2 in Spain, Italy, the United Kingdom, France, and the United States. Therefore, Brazilian public health experts endorse and recommend social distancing measures. This consensus may not exist among CHWs, likely due to conflicting sources of information, some of which deny the importance of social distancing measures for controlling the pandemic.

The present work describes how the COVID19 pandemic is perceived by CHWs who work in poor communities or slums in Brazil as members of the PHC team in the public sector. This study follows an observational and exploratory design, and focuses on understanding the social dynamics of the COVID-19 pandemic within low-income communities.

\section{Material and methods}

We followed the "snowball" procedure [20] to distribute a cross-sectional survey to CHWs who reported working in slums. First participants were contacted using a database from a previous research study [15] and were encouraged to share the questionnaire with other colleagues. The research included a random sample of 775 CHWs operating in 368 municipalities in the 26 Brazilian states. At a confidence level of $95 \%$, results of the survey were subject to a maximum sampling error of $4 \%$. The questionnaire was adaptable to different screen formats to enable its completion and distribution in different mobile devices.

While the survey was online - from May 25 to June 17, 2020 - cases of COVID-19 were mostly community-based, i.e. result of community spread, as opposed to being imported from outside Brazil [21].

The research used the terms "slums" and "lowincome communities" as synonyms, following their recommended usage in the Brazilian literature [22]. Thus, the participant sample included CHWs who self-reported working in "slums and low-income communities".

Notably, in many situations, the use of the term "slums" to designate an area with precarious housing is considered to be pejorative and stigmatizing [23]. Moreover, as Perlman points out, there is no consensual definition for "slums" by public agencies and literature. She also argues that it is difficult to precisely estimate the number of residents in a "slum". However, the author states that a slum can be described as an area inhabited by low-income individuals who perceive themselves as stigmatized and distrust public agencies. In a highly socially unequal country like Brazil, the residents of slums are highly affected by unemployment, lack of political representation, and lack of protection against criminals [24].

Leeds and Cavalcanti also point out that the uniqueness of the slums as an urban area in Brazil lies in the fact that they constitute "areas of natural growth," i.e. they develop unrestrictedly by the institutional regulation of formal cities [23].

The collected data included a demographic profile of the participants and their perceptions regarding their own working conditions in the slums, as well as on the receptivity of residents to social distancing measures. We used the perception of safety of CHWs activity in the context of the COVID-19 pandemic at the time of the research, as an explanatory variable to 
Table 1

Respondent profiles and status of CHWs during the COVID-19 pandemic in Brazil $(n=775)$

\begin{tabular}{|c|c|c|}
\hline Variable & $\%$ & $\begin{array}{c}\text { Confidence } \\
\text { interval }(95 \%)\end{array}$ \\
\hline \multicolumn{3}{|l|}{ Gender } \\
\hline Female & 84 & {$[81 ; 86]$} \\
\hline Male & 16 & {$[13 ; 19]$} \\
\hline \multicolumn{3}{|l|}{ Schooling } \\
\hline Completed high school & 65 & {$[61 ; 68]$} \\
\hline Completed higher education & 30 & {$[27 ; 33]$} \\
\hline Completed middle school & 6 & {$[04 ; 08]$} \\
\hline \multicolumn{3}{|l|}{ Age } \\
\hline Equal to or less than 32 years old & 10 & {$[08 ; 12]$} \\
\hline 41 years or older & 50 & {$[46 ; 54]$} \\
\hline 50 years or older & 20 & {$[17 ; 23]$} \\
\hline \multicolumn{3}{|l|}{ Time in the profession } \\
\hline Works as CHA for 13 years or more & 50 & {$[46 ; 54]$} \\
\hline Works as CHA for 20 years or more & 20 & {$[17 ; 23]$} \\
\hline \multicolumn{3}{|l|}{ Conditions during the COVID- 19 pandemic } \\
\hline Unit working normally & 67 & {$[64 ; 70]$} \\
\hline Current salary & 96 & {$[94 ; 97]$} \\
\hline Goal of the unit unchanged & 27 & {$[24 ; 30]$} \\
\hline Conducted home visit in the last 14 days & 76 & {$[73 ; 79]$} \\
\hline $\begin{array}{l}\text { Received training to guide social } \\
\text { distancing and individual hygiene }\end{array}$ & 34 & {$[30 ; 37]$} \\
\hline $\begin{array}{l}\text { The health unit provided personal } \\
\text { protective equipment }\end{array}$ & 61 & {$[57 ; 64]$} \\
\hline $\begin{array}{l}\text { Cough, fever, tiredness, and shortness } \\
\text { of breath in the last } 14 \text { days }\end{array}$ & 18 & {$[15 ; 21]$} \\
\hline Feeling of being unsafe while working & 87 & {$[84 ; 89]$} \\
\hline
\end{tabular}

calculate the odds ratio $(\theta)$ categorical variables. The mathematical expression for $\theta$ for categorical variables is: $\theta=((a * D) /(b * c))$. Results are reported with $95 \%$ confidence intervals.

\section{Results}

In recent qualitative studies that sample CHWs [11, 12], CHWs were predominantly female and most of them college-educated $[11,25]$ - despite the only education requirement for CHWs in Brazil is elementary education. Such studies also indicated that the age of CHWs is averagely between 40 and 45 years $[25,26]$. As shown in Table 1, the sample of CHWs that participated in this study was predominantly female, with an average age of 43 years, consistent with previous studies. Circa fifty percent of the CHWs have been working as a CHW for more than 13 years. Two out of ten CHWs have been working as a CHW for more than 20 years.

We found that $76 \%$ of CHWs performed house calls in the 14 days prior to their response to the survey, although only a small proportion (34\%) received training to advice patients on social distancing and
Table 2

Social mobilization, fear, and adherence to social isolation in the slums according to the perception of CHWs $(n=775)$

\begin{tabular}{lcc}
\hline Variable & $\%$ & $\begin{array}{c}\text { Confidence } \\
\text { interval }(95 \%)\end{array}$ \\
\hline Collective mobilization & 78 & {$[75 ; 80]$} \\
No & 22 & {$[19 ; 25]$} \\
Yes & & \\
Population avoids contact with CHWs & 51 & {$[47 ; 57]$} \\
No & 49 & {$[45 ; 52]$} \\
Yes & & \\
Fear of attending primary care clinic & 33 & {$[29 ; 36]$} \\
No & 67 & {$[63 ; 70]$} \\
Yes & & \\
Level of adherence to social isolation & 40 & {$[36 ; 43]$} \\
Low & 46 & {$[42 ; 50]$} \\
Medium & 14 & {$[11 ; 16]$} \\
High & & \\
Determinants of the decision of social isolation in slums \\
Had to work & 37 & {$[33 ; 40]$} \\
Influence of television and radio & 23 & {$[20 ; 26]$} \\
Negationism & 13 & {$[10 ; 15]$} \\
Social media & 12 & {$[10 ; 14]$} \\
Influence of neighbors & 7 & {$[05 ; 09]$} \\
Fear of falling ill & 6 & {$[04 ; 08]$} \\
Influence of CHWs & 2 & {$[01 ; 03]$} \\
\hline
\end{tabular}

individual hygiene, two important measures against COVID-19 infection.

During the data collection period, COVID-19 was already affecting the functioning of primary care clinics, as $61 \%$ of CHWs reported receiving personal protective equipment. A significant proportion of CHWs (18\%) reported symptoms of COVID-19 (fever, tiredness, and shortness of breath) in the 14 days prior to their response to the questionnaire (Table 1). Moreover, $87 \%$ of participants claimed that they worked while feeling unsafe regarding their exposure to the disease, suggesting that perception of fear was common among CHWs, even though their primary care clinic reduced their assistance goals (only 27\% of CHWs reported that the expectation for the accomplishment of assistance goals of their clinic remained the same as before the pandemic).

The majority of CHWs were pessimistic about the spontaneous mobilization of the residents of slums against COVID-19 (Table 2). Only 22\% identified some type of collective actions among residents, and $14 \%$ indicated that adherence to social distancing was high or very high. On the other hand, $86 \%$ indicated that adherence to social distancing was non-existent, very low, low, or regular.

The CHWs also claimed that fear regarding the COVID-19 pandemic was notably spread. Two out of three participants suggested that patients were afraid to attend the primary care clinic. Likewise, half of 


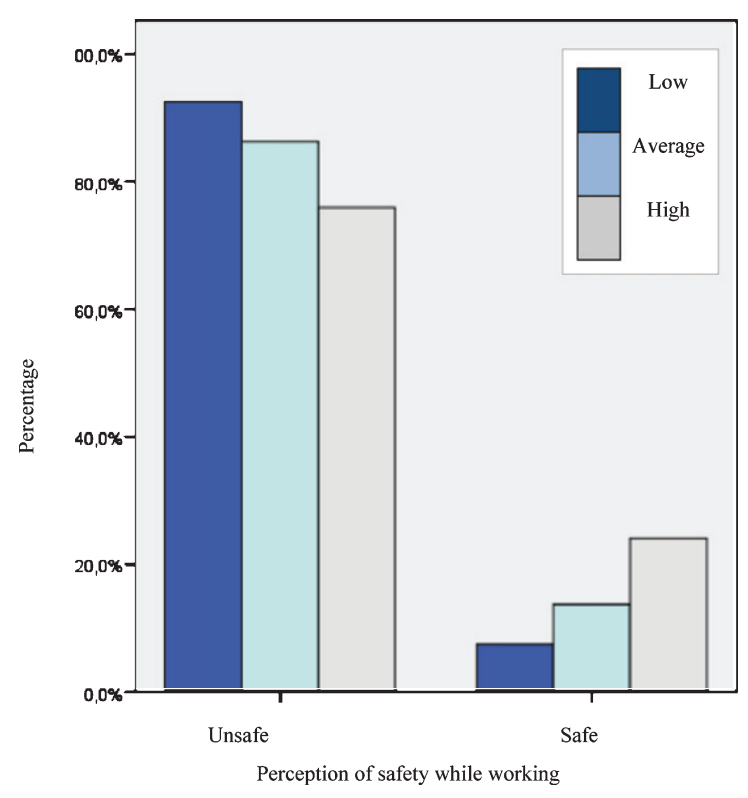

Fig. 1. Work insecurity and adherence of the slum population to social distancing; $n=775$.

the informants report that the population had avoided interacting with them.

According to CHWs, the necessity to work, the influence of traditional media, negationism, and misinformation on social media are major causes of low adherence to social distancing. They also perceived that they have little influence on patient decisions concerning social distancing. Only $2 \%$ of respondents indicated that their counseling are influential to residents.

Figures 1, 2 and 3 show that the perceptions of being unsafe regarding their exposure to COVID-19 infection among CHWs reduce when the population adhere to social distancing (Fig. 1) or mobilize spontaneously (Fig. 2), or when they report receiving some kind of training on the measures to face COVID-19 (Fig. 3).

Figure 1 shows that the CHWs' fear of getting infected while carrying out their activities is inversely proportional to adherence to social distancing. When adherence to social distancing is low, more than $90 \%$ of CHWs report feeling insecure; when adherence to distancing is moderate, the number is higher than $85 \%$, and when adherence to distancing is high, it drops below $80 \%$.

The insecurity among CHWs in carrying out their activities was reduced proportionally when they perceived collective mobilization of the population in the slums against COVID-19 as high (Fig. 2). When there

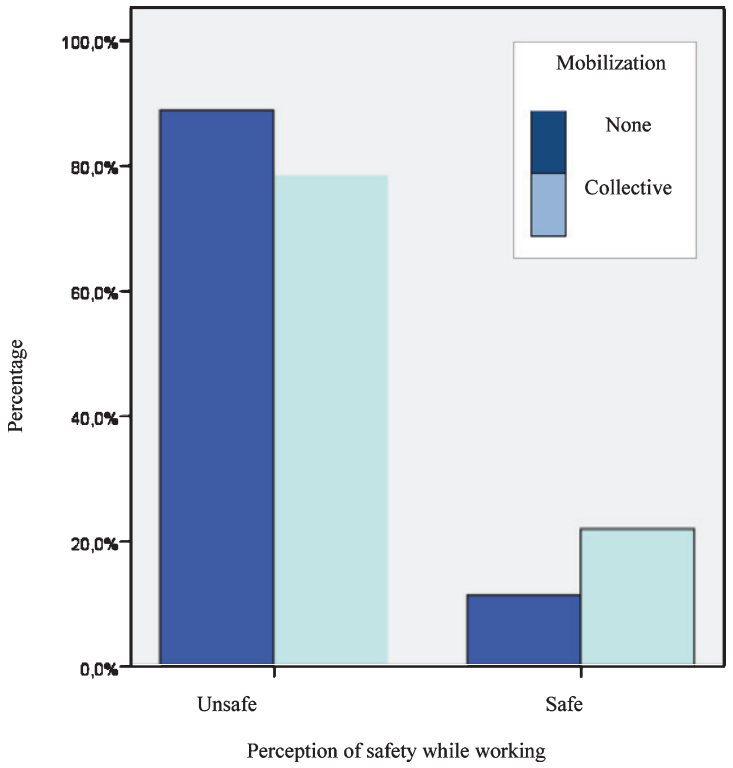

Fig. 2. Insecurity in the activity and collective mobilization of the population in the slums; $n=775$.

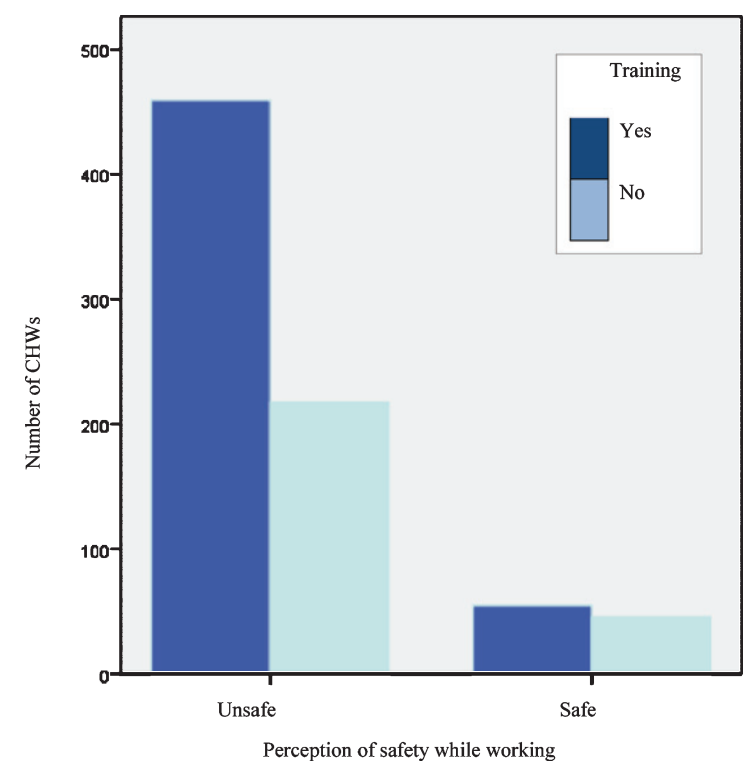

Fig. 3. Insecurity in the activity and training on the COVID-19 pandemic; $n=775$.

was no community mobilization, $85 \%$ of the respondents reported perceptions of insecurity, whereas when collective mobilization was present in the community, the number was below $80 \%$.

On the one hand, based on CHWs' responses, when there was high collective mobilization among the population, the insecurity of CHWs to develop their activities decreased. However, the values were 


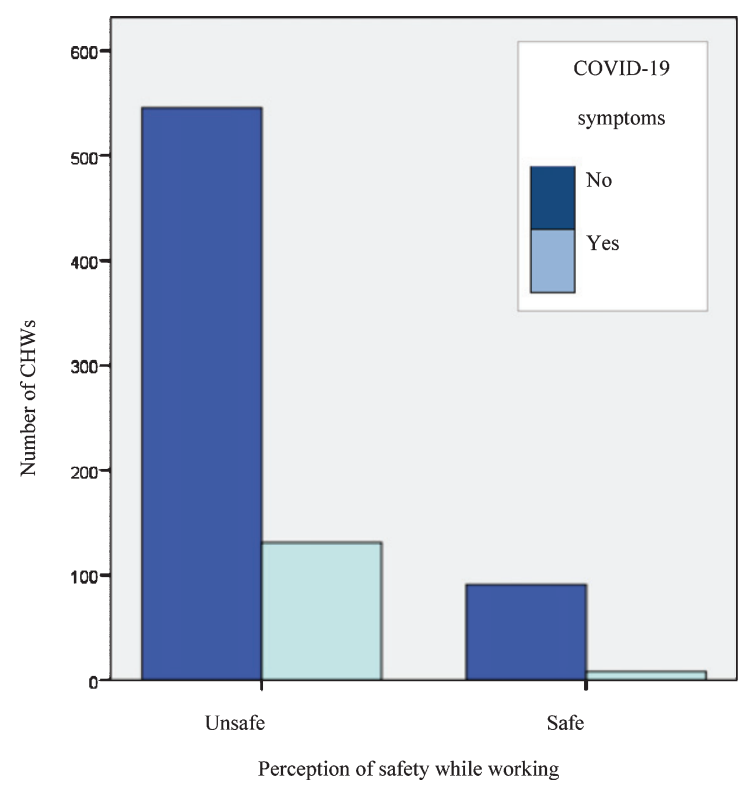

Fig. 4. Work insecurity and symptoms of COVID-19 in the last 14 days; $n=775$.

still quite high, suggesting an elevated degree of awareness among CHWs regarding the risks and consequences of getting sick.

Moreover, the insecurity regarding the possibility of getting infected while carrying out their activities was associated with training on how to handle the COVID-19 (Fig. 3). Among CHWs who received training, the perception of insecurity to perform their work activities was lower than in those who did not receive training. These results highlight the importance of disseminating information among CHWs about COVID-19 and social distancing measures.

We also found that the perception of safety when performing in slums was nearly zero among CHWs who reported cough, fever, tiredness, and shortness of breath in the 14 days prior to their participation in this study (Fig. 4).

Table 3 shows the results of odds ratio calculations in which the dependent variable is work insecurity during the pandemic. The probability that a CHW reports feeling insecure was 2.2 times higher when they perceived that the population was not engaged and 2.6 times higher when they perceived low adherence to social distancing measures. We found that the perception of insecurity was significantly affected by whether the CHW perceives that the community avoids them, whether they have received training, and whether they have experienced COVID-19 symptoms.
Table 3

Odds ratio for the perception of insecurity of CHWs working in slums during the COVID-19 pandemic- Brazil. 2020

\begin{tabular}{lcc}
\hline $\begin{array}{l}\text { Condition informed or } \\
\text { perceived by the CHWs }\end{array}$ & Odds ratio & Confidence interval \\
\hline $\begin{array}{l}\text { Noted that the population } \\
\text { avoids contact }\end{array}$ & 1,6 & $(1,2 ; 2,1)^{*}$ \\
$\begin{array}{l}\text { Had no training } \\
\text { Noted the lack of collective } \\
\text { mobilization }\end{array}$ & 1,9 & $(1,1 ; 2,7)^{*}$ \\
$\begin{array}{l}\text { Reports COVID-19 } \\
\text { symptoms }\end{array}$ & 2,2 & $(1,3 ; 3,7)^{*}$ \\
$\begin{array}{l}\text { Observed low adherence to } \\
\text { social isolation }\end{array}$ & 2,6 & $(1,2 ; 4,3)^{*}$ \\
${ }^{*} P$-value: 0.05. & & $(1,2 ; 4,7)^{*}$ \\
\end{tabular}

\section{Discussion}

Confirming the findings of Lotta [27], this research shows CHWs are highly focused on street-level bureaucracy. The research offers insight into the possibilities and limitations of CHWs' contributions to public health in the context of the recent COVID19 pandemic, which imposes unexpected challenges on the usual modes of interaction between public health officers and poor communities. This research provides evidence that these challenges have been ignored or minimized in policy prescriptions for PHC, especially regarding the handling of unexpected and adverse events.

Our data indicate that the negationist agenda of the federal, and eventually of state and municipal governments, increases the challenges to the performance of CHWs within low-income communities. The negationism of the federal government, in particular, prevented the consensus on the necessity of social distancing, business closures and other measures to face the COVID-19 pandemic [28].

In this scenario, it is inadvisable to think the pandemic in slums is an issue that only has local solutions. It is essential to consider how the lack of coordination of national, regional, and local initiatives impaired the society as a whole. By the time this research was conducted, slums have especially high rates of COVID-19 [29], evidencing the failure of public policy concerning the pandemic, tragically affecting the low-income population throughout Brazil.

We showed that negationism also constrains the activity of CHWs by discouraging spontaneous mobilization in poor communities, thus making CHWs feel unsafe in their profession and likewise making residents feel afraid to interact with health professionals. It is noteworthy that most CHWs did not 
receive training on the risks of COVID-19 from their local or regional health departments. Thus, untrained CHWs reported that they feel insecure when performing their tasks, even their regular ones, those unrelated to facing the pandemic. Moreover, such avoidance of residents in having contact with CHWs indicate a crisis of confidence concerning the structure of the health system on the primary care level.

Despite wide broadcast in the traditional media regarding the need to provide personal protective equipment for health professionals, 39\% of CHWs reported not receiving any kind of protective equipment from their respective clinics, compromising their safety and facilitating the transmission of the new Coronavirus among them and residents. The risks associated with this lack of provision are evident when two out of ten CHWs reported symptoms of COVID-19 infection. Additionally, the majority of symptomatic CHWs reported having performed house calls either way.

Current evidence shows that SARS-CoV-2 is transmitted through close contact between people. The World Health Organization (WHO) recommends the use of personal protective equipment, not only for professionals who deliver healthcare services in clinics, but also for those who deliver home care. According to the WHO, health professionals who treat patients with COVID-19 should always take precautions while in further contact with other people [30-33]. In fact, different kinds of organizations also present difficulties in protecting their workers from the new Coronavirus [34].

Although the use of personal protective equipment (PPE) is the most common precaution to prevent infection, other additional precautions may protect health workers and their patients against SARS-CoV2 , such as social distancing and systematic personal hygiene. We showed that only $34 \%$ of CHWs received training to advise on the prevention of COVID19 during home visits. Moreover, once adequately trained, they can educate residents about personal hygiene and cleanliness of the surfaces and possibly convince residents that it is important to stay home.

Research has suggested that CHWs can provide health surveillance during the pandemic, given their direct interactions with the community's residents. However, holding CHWs accountable for health surveillance should be carried out with caution, as collecting patients' private information is not on the job description of CHWs [35].

It is worth remembering that, in the context of the pandemic, the possibility of CHWs interference in the conduct of the population about social distancing is reported in this research as quite low. The low level of education among residents of these communities associated with a large number of unemployed and informal workers poses a challenge to wide adherence to social distancing measures, especially while coping with negationist governmental authorities.

Four out of ten $\mathrm{CHWs}$ perceive that slum residents encounter difficulties in adhering to social distancing because of their need to work. The low coverage of the national income transfer policy, i.e. a federal program to provide economic relief to low-income families, hampers the adherence to social distancing in communities [15, 36, 37]. Loss of income poses difficulties to buy food and other essential goods. The search for informal labor contributes to the circulation of people in the slums, making them particularly vulnerable to the spread of the new Coronavirus. It is also worth remembering that the poor housing conditions in these communities make it difficult for residents to stay indoors.

It is therefore unsurprising that $\mathrm{CHW}$ serceive that social mobilization and adherence to social distancing in slums are minimal. However, this research indicates that when CHWs perceive that there is social mobilization in the community, it significantly reduces their perception of insecurity and fear as they perform their duties.

The main limitation of this study concerns the implicit bias in the snowball sampling method. However, the snowball sampling procedure appeared adequate for this study, as the progression of the COVID-19 pandemic hampered the explicit recruitment of CHWs. Besides, participants with more connections are more likely to be selected in this sampling approach enhanced the size of the sample. We minimize the bias limitation by extending the data collection period in order to recruit more participants, enabling the sample to be balanced to represent as most regions as possible. Bias was also mitigated as the initial recruiting was randomly made from an existing CHW database comprising the entire CHWs that works in Rio de Janeiro territories, and not from already known agents.

\section{Conclusions}

It is possible to conclude that the activities of CHWs in slums during the COVID-19 pandemic 
present the same complexities that existed before the pandemic, although at a higher level. Transformations of the organization of work and in the work environment affect the workers' perception of insecurity. The areas where CHWs work are usually marked by constant demographic transformation, a usually high spread of infectious diseases, and a high prevalence of chronic conditions. These dangerous conditions grew stronger during the pandemic, which put even more pressure on the health system, and consequently, on the CHWs, who act on the front lines of this complex system.

Mass dissemination of information on the extreme risk of COVID-19 in social networks and traditional media could favor receptivity to the work of the CHWs and increase adherence to social distancing in the slums. However, promoting social distancing is not part of the Federal Executive's agenda, even though SARS-CoV-2 has strongly affected Brazilian low-income communities.

CHWs are paramount in primary care frameworks in developing countries. Their work within communities varies from advocacy for primary care, socio-economic research, socio-environmental research, and assistance. Therefore, they are especially exposed to harmful situations. However, the COVID-19 pandemic has increased the tensions to which these workers are exposed.

This research highlights important aspects concerning not only work conditions of CHWs, but also the precarious conditions of the communities where they perform. Thus, this papers contributes to healthcare managers and providers in order to mitigate aspects that hamper the effectiveness of primary health care in poor communities, improving the quality of health services.

\section{Acknowledgments}

Paulo Victor Rodrigues de Carvalho acknowledges the funding agencies FAPERJ (Fundação Carlos Chagas Filho de Amparo à Pesquisa do Estado do Rio de Janeiro) and CNPq (Conselho Nacional de Desenvolvimento Científico e Tecnológico).

\section{Conflict of interest}

The authors have no conflicts of interest to declare.

\section{References}

[1] Bhutta ZA, Lassi ZS, Pariyo G, Huicho L. Global experience of community health workers for delivery of health related millennium development goals: a systematic review, country case studies, and recommendations for integration into national health systems. Glob Health Workforce Alliance. 2010;1(249):61.

[2] Liu A, Sullivan S, Khan M, Sachs S, Singh P. Community Health Workers in Global Health: Scale and Scalability. Mt Sinai J Med J Transl Pers Med. 2011;78(3):419-35.

[3] Wennerstrom A, Rush CH. The Terminology of Community Health Workers. Am J Public Health. 2016;106(8):e10-e10.

[4] Iyengar MS, Florez-Arango JF. Decreasing workload among community health workers using interactive, structured, rich-media guidelines on smartphones. Technol Health Care. 2013;21(2):113-23.

[5] Bousquat A, Giovanella L, Campos EMS, Almeida PF de, Martins CL, Mota PH dos S, et al. Primary health care and the coordination of care in health regions: managers' and users' perspective. Ciênc Saúde Coletiva. 2017;22(4):114154.

[6] Giovanella L. Primary care in European Union countries: configurations and organizational reforms in the 1990s. Cad Saúde Pública. 2006;22(5):951-63.

[7] Holness DL, Hayes L, Nichol K, Kudla I, Nincic V. Joint health and safety committees - What is their impact in the acute care hospital? Work. 2016;53(4):763-73.

[8] Paim J, Travassos C, Almeida C, Bahia L, Macinko J. The Brazilian health system: history, advances, and challenges. The Lancet. 2011;377(9779):1778-97.

[9] Folha de Sao Paulo. Em derrota a Bolsonaro, Moraes decide que estados têm autonomia para impor isolamento social - 08/04/2020 - Poder - Folha [Internet]. 2020 [cited 2020 Jun 25]. Available from: https://www1.folha.uol.com.br/poder/2020/04/em-derrotaa-bolsonaro-moraes-decide-que-estados-tem-autonomiapara-impor-isolamento-social.shtml?origin=folha.

[10] Costa N do R. The Family Health Strategy: primary health care and the challenge of Brazilian metropolises. Ciênc Saúde Coletiva. 2016;21(5):1389-98.

[11] Barreto IC de HC, Pessoa VM, Sousa M de FA de, Nuto $\mathrm{S}$ de AS, Freitas RWJF de, Ribeiro KG, et al. Complexity and potentiality of the Community Health Workers' labor in contemporary Brazil. Saúde Em Debate. 2018;42(spe1):114-29.

[12] Justo CMP, Gomes MH de A, Silveira C. Limits and constraints of the instruments that control the work of community health agents in the Family Health Strategy. Saúde E Soc. 2015;24(2):594-606.

[13] Lotta GS. Local knowedge and citizenship: the communitarian health agents. Saúde E Soc. 2012;21(suppl 1):210-22.

[14] Morosini MV, Fonseca AF. Community workers in Primary Health Care in Brazil: an inventory of achievements and challenges. Saúde Em Debate. 2018;42(spe1):261-74.

[15] Bellas HC, Jatobá A, Bulhões B, Koster I, Arcuri R, Burns C, et al. Effects of Urban Violence on Primary Healthcare: The Challenges of Community Health Workers in Performing House Calls in Dangerous Areas. J Community Health. 2019;44(3):569-76.

[16] Valor Econômico. "Vai estourar", diz brasileira professora em Harvard sobre a crise no Brasil [Internet]. Valor Econômico. 2020 [cited 2020 Jun 25]. Available from: https://valor.globo.com/eu-e/noticia/2020/05/29/vai- 
estourar-diz-brasileira-professora-em-harvard-sobre-acrise-no-brasil.ghtml.

[17] Engstrom E, Melo E, Giovanella L, Mendes A, Grabois $\mathrm{V}$, Mendonça MHM de, et al. Recomendações para a organização da Atenção Primária à Saúde no SUS no enfrentamento da Covid-19. 2020;.

[18] Bier VM. The Gower handbook of extreme risk: assessment, perception and management of extreme events [Internet]. 2016 [cited 2020 Jun 25]. Available from: http://www.vlebooks.com/vleweb/product/openreader?id= none\&isbn $=9781317029946$.

[19] Power M. Risk, social theories, and organizations. Oxf Handb Sociol Soc Theory Organ Stud Oxf Oxf Univ Press. 2014;370-92.

[20] Goodman LA. Snowball Sampling. Ann Math Stat. 1961;32(1):148-70.

[21] Hill CA, Dean E, Murphy J, editors. Social media, sociality, and survey research. Hoboken, New Jersey: John Wiley \& Sons, Inc; 2013. pp. 1.

[22] Araujo FO de, Salles J do N, Freitas A. Um passarinho na mão ou dois voando? dilemas do grupo carteiro amigo entre se expandir organicamente na favela da rocinha ou se arriscar para além da zona de conforto. REAd Rev Eletrônica Adm Porto Alegre. 2017;23(2):351-69.

[23] Leeds A, Cavalcanti M. How Much is a Favela Worth. Sociol Antropol. 2018;8(3):831-48.

[24] Perlman JE. Favela four decades of living on the edge in Rio de Janeiro [Internet]. Oxford: Oxford University Press; 2010 [cited 2020 Jun 25]. Available from: http://public.ebookcentral.proquest.com/choice/publicfull record.aspx? $\mathrm{p}=535439$

[25] Simas PRP, Pinto IC de M. Health work: portrait of community workers in the Northeast region of Brazil. Ciênc Saúde Coletiva. 2017;22(6):1865-76.

[26] Moreira DC, Soares DA, Castro CPD, Bispo Júnior JP. Family Health Support Center's work to strengthening of primary care: experiences of community workers. Physis Rev Saúde Coletiva [Internet]. 2019 [cited 2020 Jun 25];29(3). Available from: http://www.scielo.br/scielo.php? script=sci_arttext\&pid=S0103$73312019000300600 \& \operatorname{tlng}=$ pt.

[27] Lotta G. Burocracia e implementação de políticas de saúde: os agentes comunitários na Estratégia Saúde de
Família [Internet]. Place of publication not identified: SCIELO EDITORA FIOCRUZ; 2015 [cited 2020 Jun 26]. Available from: http://www.jstor.org/stable/10.7476/ 9788575415481 .

[28] O Globo. Da 'gripezinha' às 50 mil mortes pela Covid19 - Jornal O Globo [Internet]. 2020 [cited 2020 Jun 26]. Available from: https://oglobo.globo.com/opiniao/dagripezinha-as-50-mil-mortes-pela-covid-19-1-24491286.

[29] Folha de Sao Paulo. Coronavírus infectou 17\% em favelas e em bairros pobres do Rio de Janeiro - 23/06/2020 Equilíbrio e Saúde - Folha [Internet]. 2020 [cited 2020 Jun 26]. Available from: https://www1.folha.uol.com.br/ equilibrioesaude/2020/06/coronavirus-infectou-17-emfavelas-e-em-bairros-pobres-do-rio-de-janeiro.shtml.

[30] Gan WH, Lim JW, Koh D. Preventing Intra-hospital Infection and Transmission of Coronavirus Disease 2019 in Health-care Workers. Saf Health Work. 2020;11(2):241-3.

[31] Mhango M, Dzobo M, Chitungo I, Dzinamarira T. COVID19 Risk Factors Among Health Workers: A Rapid Review. Saf Health Work. 2020 Jun;S2093791120302961.

[32] World Health Organization. Rational use of personal protective equipment (PPE) for coronavirus disease (COVID-19): interim guidance, 19 March 2020. 2020 [cited 2020 Jul 13]; Available from: https://apps.who.int/iris/handle/10665/331498.

[33] Omidi L, Moradi G, Mostofi Sarkari N. Risk of COVID19 infection in workplace settings and the use of personal protective equipment. Work. 2020;66(2):377-8.

[34] Garzillo EM, Monaco MGL, Spacone A, Inglese E, Lamberti M, Pompei D. SARS-CoV-2 emergency in the workplace: are companies ready to protect their workers? A cross-sectional survey. Int J Occup Saf Ergon. 2020;0(ja): $1-20$.

[35] Cernavin O, Lemke-Goliasch P. Occupational Health and Social Resources. Int J Occup Saf Ergon. 2001;7(4):543-60.

[36] Jatobá A, Bellas HC, Koster I, Arcuri R, Vidal MCR, de Carvalho PVR. Patient visits in poorly developed territories: a case study with community health workers. Cogn Technol Work. 2018;20(1):125-52.

[37] Jatobá A, Bellas HC, Bulhões B, Koster I, Arcuri R, de Carvalho PVR. Assessing community health workers' conditions for delivering care to patients in low-income communities. Appl Ergon. 2020;82:102944. 